- Márcio Brudniewski

- Maria Paula M. Ferro

- André P. Schmidt

\section{Anestesia para pneumonectomia direita em criança com criptococose pulmonar}

\author{
Disciplina de Anestesiologia da Faculdade de Medicina \\ da Universidade de São Paulo, São Paulo
}

INTRDDUCॄÃa

Pneumonectomia direita em pediatria é procedimento pouco descrito na literatura, sem discussão ou consenso a respeito da técnica anestésica mais apropriada para esses casos.

\section{RELATI DO CASD}

Paciente de 4 anos para realização de pneumonectomia direita devido a um criptococoma pulmonar não responsivo a tratamento clínico. A paciente recebeu midazolam $7,5 \mathrm{mg}$, via oral como medicação pré-anestésica. Após venóclise em membro superior direito (cateter $24 \mathrm{G}$ ), foi submetida à anestesia geral com propofol, sufentanil e rocurônio. Manutenção com sevoflurano. Foi realizada peridural torácica (T8-9) com passagem de cateter sem intercorrências e infusão contínua de ropivacaína $0,2 \% 1 \mathrm{ml} / \mathrm{h}$. A monitorização foi composta por eletrocardioscópio, oximetria de pulso e pressão arterial média invasiva (cateter $22 \mathrm{G}$ ) em artéria radial esquerda, pressão venosa central em veia subclávia direita com cateter duplo lúmen pediátrico. Outros dois acessos venosos foram obtidos (cateter $18 \mathrm{G}$ ) em ambas as veias safenas. Realizada intubação orotraqueal com tubo 5,0 e tentativa, sem sucesso, de passagem do bloqueador brônquico pediátrico guiado por fibrobroncoscopia. Intubação seletiva de brônquio-fonte esquerdo guiado por fibrobroncoscopia e posicionamento em decúbito lateral esquerdo. Após toracotomia e manipulação da árvore traqueobrônquica, a paciente evoluiu com impossibilidade de ventilação devido à migração do tudo endotraqueal (TET) e bronco-espasmo grave, apresentando hipóxia e bradicardia, prontamente revertidas após reposicionamento do TET e administração de salbutamol spray. O restante do procedimento evoluiu com dificuldades ventilatórias, necessitando de altas pressóes de via aérea para manter oxigenação adequada. Após o procedimento, a paciente foi transferida para a UTl e apresentou boa evolução pós-operatória.

CDNCLUSÃロ

Pneumonectomia direita em pediatria é um procedimento raro, considerado tecnicamente difícil e poucos casos estão descritos na literatura. Podemos concluir que o bloqueador brônquico é importante para a proteção do pulmão sadio de secreções provenientes do pulmão acometido, porém ainda é necessário mais treinamento para a utilização em pediatria. Monitorização invasiva, acessos venosos calibrosos e cuidados pós-operatórios para prevenção de síndrome pós-pneumonectomia também são fundamentais.

REFERÊNCIA

1. Eren $\mathrm{S}$, et al. Pneumonectomy in children for destroyed lung and the long-term consequences. J Thorac Cardiovasc Surg. 2003;126(2):574-81.

\section{Endereço para correspondência:}

Márcio Brudniewski

Rua Pedroso Alvarenga, 372 - apto. 61 - Itaim Bibi

São Paulo (SP) - CEP 04531-000

Tel. (+55 11) $9613-2733$

E-mail: marciobrudi@hotmail.com 